\title{
O retorno do pesadelo: um estudo sobre a luta da memória contra o esquecimento
}

The Return of the Nightmare: A Study on the Struggle of Memory versus

Forgetting

Le retour du cauchemar: une étude sur la lutte pour la mémoire contre l'oubli

Myrian Sepúlveda dos Santos

\section{(2) OpenEdition}

\section{Journals}

\section{Edição electrónica}

URL: http://journals.openedition.org/rccs/10324

DOI: $10.4000 /$ rccs.10324

ISSN: 2182-7435

Editora

Centro de Estudos Sociais da Universidade de Coimbra

Edição impressa

Data de publição: 1 maio 2020

Paginação: 103-122

ISSN: 0254-1106

\section{Refêrencia eletrónica}

Myrian Sepúlveda dos Santos, «O retorno do pesadelo: um estudo sobre a luta da memória contra o esquecimento », Revista Crítica de Ciências Sociais [Online], 121 | 2020, posto online no dia 15 abril 2020, consultado o 17 abril 2020. URL : http://journals.openedition.org/rccs/10324 ; DOI : https:// doi.org/10.4000/rccs. 10324 


\title{
MYRIAN SEPÚLVEDA DOS SANTOS
}

\section{O retorno do pesadelo: um estudo sobre a luta da memória contra o esquecimento}

\begin{abstract}
Este artigo propõe uma análise de diferentes tipos de memória frente a questões relacionadas com políticas da memória, falsificação da história e amnésia coletiva no contexto atual de crise econômica, fragmentação dos trabalhadores e predominância das redes sociais nos processos comunicativos. Procura-se demonstrar que existem diversas formas de uma sociedade lutar contra o esquecimento: através da literatura de testemunho, de casos de pós-memória e de arquivos. Em qualquer destes casos, há necessidade de uma abordagem crítica para que o compromisso com o passado, também compreendido como dever da memória, se cumpra em prol de uma postura ética apta a lidar com responsabilidades e políticas de reparação.
\end{abstract}

Palavras-chave: arquivos; herança cultural; literatura de testemunho; memória coletiva.

\section{A falsificação da história}

Estamos terminando a segunda década do século XXI com revisões históricas que desprezam testemunhos e a documentação armazenada. As chamadas fake news se multiplicam e são reproduzidas maciçamente pelos novos meios de comunicação. Mitos diversos e absurdos se impõem, com a rejeição, inclusive, de descobertas científicas que já faziam parte do senso comum, como é o caso da crença atual nas teorias sobre a "Terra plana". Para nós, no Brasil, a amnésia coletiva voltou a ser pesadelo. Em 2018, diversos brasileiros questionaram o conteúdo do vídeo que trazia informações sobre o extremismo de direita publicado pela Embaixada da Alemanha no Brasil. ${ }^{2}$ Alguns utilizadores brasileiros do Twitter "corrigiram" os dizeres

\footnotetext{
${ }^{1}$ Ver, por exemplo, o documentário $A$ Terra éplana [Behind the Curve, no original] disponível em uma das maiores companhias de transmissão de vídeos através da internet. Consultado a 03.06.2019, em https://www.netflix.com/br/title/81015076.

${ }^{2}$ Queiroga, Louise (2018), "Embaixada da Alemanha explica o nazismo e é contestada por brasileiros", O Globo, 17 de setembro. Consultado a 10.06.2019, em https://oglobo.globo.com/sociedade/ embaixada-da-alemanha-explica-nazismo-e-contestada-por-brasileiros-2-23074988.
} 
publicados pela Embaixada alemã, considerando que o Terceiro Reich teria sido um governo de esquerda e não de extrema-direita. Esta afirmação foi também defendida em março de 2019 pelo ministro das Relações Exteriores do Brasil, com ampla divulgação pela mídia. ${ }^{3}$ A construção do passado, com claro teor político, passou assim a ser realizada por ministros e pelo chefe de Estado sem qualquer referência a documentos, arquivos, análises de especialistas e em claro confronto com testemunhos. Em manifestações com milhares de pessoas têm-se visto cartazes enaltecendo o período de ditadura militar (1964-1985), que antes era consensualmente apresentado pela imprensa como período de suspensão de liberdades democráticas. ${ }^{4}$ Parte da população é incentivada pelas diversas homenagens feitas por Jair Bolsonaro, atual presidente eleito, a esse período da história brasileira e, inclusive, a um dos maiores torturadores da ditadura, Carlos Alberto Brilhante Ustra, chefe do Destacamento de Operações de Informações. ${ }^{5}$ A pergunta que podemos nos fazer é se os manifestantes não têm informações sobre a censura e violação dos direitos humanos nesse período ou se estes são aspectos que passaram a ser valorizados?

As últimas décadas do século Xx foram consideradas por muitos como a "era da memória", pois nelas se observou a multiplicação de arquivos, museus, monumentos, literatura testemunhal, filmes e romances históricos, bem como de estudos acadêmicos sobre memória e tradição (Lavabre, 2000). Aparentemente, a era da exaltação da memória não cumpriu seu dever. Com a ascensão de novas forças políticas, defrontamo-nos com o risco de que a censura e a historiografia falaciosa se tornem uma ameaça crescente ao conhecimento sobre o passado.

É neste novo contexto que concentro minha atenção nos atributos da memória que resistem às normas e padrões impostos pelo poder. O objetivo desse artigo é analisar as diferentes formas pelas quais os indivíduos lutam contra o esquecimento. $\mathrm{O}$ tema da luta da memória contra o esquecimento

\footnotetext{
3 Jovem Pan (2019), "Ministro das Relações Exteriores diz que nazismo era regime 'de esquerda', 29 de março. Consultado a 10.06.2019, em https://jovempan.uol.com.br/noticias/brasil/ministrodas-relacoes-exteriores-diz-que-nazismo-era-regime-de-esquerda.html.

${ }^{4}$ Embora não seja nosso objetivo fazer uma análise das manifestações populares que aconteceram no Brasil na última década, podemos destacar que as jornadas de junho de 2013 foram um marco no sentido de acelerar o movimento de contestação ao governo do Partido dos Trabalhadores, o qual, associado às denúncias de corrupção, teve como resultado o impeachment da presidente Dilma Roussef em 2016. Ao longo de 2015 e 2016 diversas manifestações populares a favor e contra o governo aglutinaram milhares de pessoas nas ruas. Nas manifestações contra o governo, caracterizadas pelo uso de vestimentas com as cores da bandeira nacional, posicionamentos a favor da ditadura militar foram constantes. ${ }^{5}$ CartaCapital (2019), "Bolsonaro volta a elogiar torturador Ustra: 'herói nacional'”, 8 de agosto. Consultado a 08.08.2019, em https://www.cartacapital.com.br/politica/bolsonaro-volta-a-elogiartorturador-ustra-heroi-nacional/.
} 
não é uma novidade, pois sabemos que o lembrar é sempre seletivo. Pensadores das mais variadas vertentes procuraram compreender as contribuições de testemunhos em contraposição às diversas versões oficiais do passado, as falhas inerentes às reconstituições, a falsificação deliberada, bem como usos e abusos da história e da memória. Aqueles que estão no poder procuram controlar e utilizar o passado em benefício próprio. Regimes autoritários esforçam-se por produzir uma versão única da história, a partir da repressão às versões dissidentes ou que não sejam oficiais.

Michael Pollak (1989) criou o conceito de "memória subterrânea" para explicar a memória de grupos que não é reconhecida pela memória oficial ou nacional. Em referência às teorias do sociólogo Maurice Halbwachs, o autor criticou a perspectiva funcionalista em que memórias individuais são sempre consideradas em conformidade com as coletivas. Halbwachs é uma referência obrigatória ao estudo da memória coletiva. Para ele, quadros ou estruturas sociais organizam nossas memórias. As memórias construídas por grupos e transmitidas em rituais e tradições são fortes e duradouras e, em grande parte, influenciam e determinam comportamentos coletivos (Halbwachs, 1925, 1968). Para Pollak, contudo, a memória de minorias marginalizadas é explicada a partir da reação ao caráter opressor, ou seja, como alternativa à imposição uniformizadora.

Tzvetan Todorov (1995) ressaltou que a luta pela memória e verdade pode surgir como o reverso do apagamento da história em contextos pós-ditatoriais, mas que nós devemos sempre preservar igualmente o direito ao esquecimento, pois o lembrar deve ser uma opção e um direito. Nas democracias, as memórias construídas respeitam as diversas visões e práticas políticas. Mais do que isso, o cuidado com memórias traumáticas tem sido cada vez maior. No Brasil, os castigos imputados aos indivíduos escravizados têm sido denunciados de forma a não vitimizar ou trazer constrangimento aos que se consideram seus descendentes.

Em que pese a importância dos estudos sobre a memória disputada ou imposta por meio da política, os estudos contemporâneos sobre memória nos mostram que há mais a compreender. A memória é tanto forma de pensamento, como seu produto; ela está presente em uma multiplicidade de práticas sociais, como arte, literatura, testemunho, relatos de descendentes, narrativas historiográficas, memórias biográficas, arquivos, videotecas e demais instituições correlatas. Não só temos diferentes tipos de memória, - uns mais ativos, outros mais passivos - como eles, enquanto forma de pensamento, modificam-se de contexto a contexto.

Paul Ricoeur (2000) procurou sistematizar diferentes formas pelas quais nós, indivíduos entrelaçados e relacionados ao imaginário coletivo, nos 
lembramos do passado. Para alguns há no seu trabalho uma fenomenologia da lembrança. Um dos pares da memória analisado por Ricoeur faz referência àquele descrito pelo filósofo Henri Bergson, na obra Matéria e memória. Bergson (1985 [1896]) descreveu dois tipos de memória: a "memória pura", como sendo a lembrança de um acontecimento no passado, e a "memória hábito", como sendo a memória que atualiza o passado a partir de ações e práticas que se automatizam. Para Ricoeur é importante identificar não só os diferentes tipos de memória, mas também perceber a relação que mantêm entre eles.

É interessante constatar que estudos recentes da neurociência, feitos por meio de imagens que detectam o funcionamento do cérebro, reiteram basicamente os tipos de memória descritos por Bergson. "Memórias explícitas e implícitas" ou, ainda, "declarativas e procedurais" podem ser relacionadas com o par "memória pura e memória hábito". Em quaisquer das classificações, no primeiro caso, indivíduos estão conscientes de eventos vivenciados, são capazes de construí-lo no presente e atribuir significados ao que se passou. No segundo caso, experiências passadas são incorporadas e influenciam ações do presente sem que indivíduos tenham esta percepção. ${ }^{6}$ A memória pura, declarativa, explícita ganha ainda muitas divisões (memória auditiva, visual, etc.). Dentre elas, destaca-se aquela feita pelo psicólogo Endel Tulving entre memória episódica e memória semântica. A primeira refere-se à lembrança de um episódio marcado no tempo e espaço, como uma data comemorativa, e a segunda, à lembrança do significado de uma situação complexa vivenciada (Tulving, 1972). Em consonância com os estudos de Ricoeur, Tulving afirma que quanto mais complexas e automatizadas se tornam as lembranças, menos consciência temos delas e mais duradouras elas são (ibidem). A atribuição de significados não diz respeito ao indivíduo ou à sociedade, em oposição, mas a processos em que ambos estão entrelaçados.

A partir destas classificações, podemos dizer que quando falamos da luta da memória contra o esquecimento, o que está em questão não é apenas o uso do passado por um ou outro grupo, ou ainda a decisão sobre o que lembrar. A luta da memória contra o esquecimento envolve também a preservação de traços da memória em contextos desfavoráveis, a reiteração da lembrança a partir de narrativas diversas, a consolidação da escrita do passado por meio de comemorações, monumentos e arquivos, e - mais do que tudo - a compreensão de que a memória que se quer preservar não

\footnotetext{
${ }^{6}$ Sobre os diversos tipos de memória presentes em estudos da psicologia social, ver Schacter e Tulving (1994).
} 
pode ser separada da visão crítica do passado, o que envolve o combate à falsificação da história e a luta pela justiça. Podemos, neste sentido, contar ainda com os escritos de Todorov (2002), que nos mostram como os regimes totalitários do século XX controlaram a memória utilizando-se de práticas como censura; restrição da circulação de informações e de formas não oficiais da memória, como narrativas orais e poesia; intimidação para que a população não procurasse se informar; uso reiterado da mentira e da propaganda; e destruição sistemática de arquivos e documentos.

\section{A memória-testemunho como resistência à falsificação da história}

Contra as falsificações da história, a literatura de testemunho tem desempenhado um papel importante, pois como afirmou o historiador e crítico literário Márcio Seligmann-Silva (2003: 8), nela temos a ver com um "real" que não se deixa reduzir. Há uma liberdade na literatura e arte que não estão presentes nas narrativas historiográficas, pois elas contribuem ao mostrarem uma alternativa à impossibilidade da representação, sempre restrita às fontes existentes.

A literatura tem exercido um papel importante na resistência à falsificação da história. São bem conhecidos os romances do escritor Milan Kundera, por exemplo, que dedicou parte de sua obra à tarefa de combater as deturpações da história feitas pelos governos autoritários da antiga Checoslováquia. Em seus contos e romances, a vida pessoal e cotidiana dos personagens entrelaça-se com a situação política do país. Embora sua tarefa não fosse a de um historiador, voltado para a reconstituição do passado a partir de uma busca impessoal e baseada em fontes, o escritor nos advertia que lutas eram travadas para se ter acesso aos laboratórios em que era possível retocar fotografias, reescrever biografias e mudar o passado (Kundera, 1987 [1978]). Em O livro do riso e do esquecimento (ibidem), romance que marcou sua narrativa pós-exílio, o primeiro conto se inicia com a descrição do discurso do dirigente comunista checo, Klement Gottwald, em 1948, assistido por centenas de milhares de cidadãos. Kundera assinala que Vladimir Clementis, uma das lideranças do Partido, foi acusado de traição quatro anos mais tarde. As fotografias oficiais que retratavam a celebração da tomada de poder foram retocadas de modo a que o traidor desaparecesse. O personagem Mirek, contudo, lembrava-se não só de Clementis, mas do que restou de sua presença, o gorro na cabeça de Gottwald. Detalhes que configuram a memória. O conto nos mostra que apesar da tentativa de controle da memória pelo discurso e propaganda oficial, havia aqueles que mantinham memórias conflitantes.

No Brasil, são muitos os relatos autobiográficos e biográficos sobre o período de ditadura militar com clara intenção de denunciar o apagamento 
na história oficial de parte do que foi vivenciado. Alguns foram escritos durante o governo militar ou logo após 1985, e outros são mais recentes. Entre os primeiros, podemos citar lembranças sofridas e traumáticas, como Em câmara lenta, de Renato Tapajós (1975). São narrativas de pessoas que participaram da militância contra o governo, sobreviveram, e deixaram lembranças de experiências atravessadas pelas tensões do período. Uma outra leva de livros foi publicada após a promulgação da Lei da Anistia, quando o exílio acabou para muitos. Nesse grupo, citamos $O$ que é isso, companheiro?, de Fernando Gabeira (1979), Os carbonários, de Alfredo Sirkis (1980) e o Batismo de sangue, de Frei Betto (1982). Esses foram livros que trouxeram memórias pessoais dos acontecimentos políticos da época, mas já descritas a partir de um certo distanciamento dos fatos ocorridos. Um terceiro conjunto de livros publicados mais recentemente apresenta uma reflexão com maior distanciamento ainda dos eventos, tanto temporal como emocional, o que não os impede de ter um forte caráter de denúncia de falsificações históricas ocorridas. Desta última leva, destacamos o livro Ainda estou aqui, de Marcelo Rubens Paiva (2015).

Marcelo Rubens Paiva ficou conhecido como escritor pelo seu primeiro livro, Feliz ano velho, publicado 33 anos antes, quando enfrentou, após um acidente, a condição de tetraplégico. Já nesse livro havia referências ao desaparecimento de seu pai, o deputado federal Rubens Paiva, torturado e morto pelos militares em 1971, quando Marcelo tinha 11 anos (Paiva, 1982). O ponto de partida do novo relato autobiográfico é seu cuidado com a mãe, a advogada Eunice Paiva, portadora de Alzheimer. A história que se desenrola nas páginas do livro é a de uma mãe de cinco filhos, que, a partir do sequestro do marido, precisou se reinventar, estudar, e encontrar uma profissão para criá-los sozinha. Em meio à dor e à luta contra um governo violento e ditatorial, Eunice se tornou advogada, defensora de direitos humanos, e, em particular dos direitos indígenas. A reconstrução da vida de Eunice se entrelaça com a do autor e de sua família e traz à tona a luta de pessoas, organizações e movimentos para esclarecer a história da repressão política do período militar.

Marcelo é filho de um desaparecido. Relatos mais detalhados sobre a prisão de seu pai apenas são fornecidos no final do livro, quando o autor relata o momento em que a doença da mãe avança e que novas informações são fornecidas pela Comissão Nacional da Verdade (CNV), em 2014. ${ }^{7}$ A ironia é que os dados sobre o passado surgem quando Eunice já tem perda

\footnotetext{
${ }_{7}$ A CNV foi um órgão transitório instituído em 2012 pelo governo de Dilma Roussef para apurar violações de direitos humanos, mas sem competência para encaminhar punições.
} 
significativa da sua memória. Memórias que correm em direções opostas. O filho prevê a morte da mãe, o que não acontece em relação ao pai, cuja perda ele sente como um processo aberto a novas narrativas, sofrimento e dor.

Rubens Paiva não era membro de nenhum dos diversos partidos clandestinos que atuavam em oposição ao regime militar; ele havia sido eleito deputado federal pelo Partido Trabalhista Brasileiro (PTB), partido criado por Getúlio Vargas e que abrigava lideranças governistas como João Goulart, o presidente deposto. Engenheiro e deputado federal cassado, e fazendo parte uma rede de jornalistas e políticos que, embora afastados do poder, detinham legitimidade junto às esferas de poder, acreditou estar imune aos atos de tortura que recaíam com maior frequência sobre os militantes dos partidos que defendiam o comunismo. Enganou-se. Conforme descrito no livro de Paiva (2015), no dia 20 de janeiro de 1971, seis sujeitos armados em trajes civis cruzaram o quintal da sua casa. Vestiu-se formalmente, colocou o relógio de pulso, umas cadernetas no bolso. Foi com dois agentes, dirigindo o Opel da esposa, prestar depoimentos. Dois dias depois estava morto. Prenderam também a esposa e uma de suas filhas, que na época tinha 15 anos. Não houve qualquer mandato de prisão, foram sequestrados. Oficialmente não havia prisões, não havia torturas, não havia mortos, nem desaparecidos.

A tortura violenta, assassinato e ocultamento do corpo de Rubens Paiva, que foi enterrado e desenterrado várias vezes, foram atos confirmados por depoimentos de militares à $\mathrm{CNV}$, mais de 40 anos após sua morte. Os espancamentos e tortura foram de tal ordem que ele não conseguiu sobreviver ao segundo dia. Por que mantiveram a esposa presa por 15 dias? Por que ela e a filha ficaram encapuzadas no mesmo local em que ele estava sendo torturado? Será que foram utilizadas para aumentar seu sofrimento? Silêncios e vazios de uma história macabra.

Após o desaparecimento de Rubens Paiva, o governo começou a dar informações contraditórias, emitindo notas sobre o seu não envolvimento o que seria entretanto desmentido pela presença do automóvel do deputado próximo ao local onde foi detido; sobre a libertação imediata e assalto, notícia que também carecia de qualquer comprovação. Mentiras de ministros e de autoridades encobrindo os crimes cometidos em instalações militares (Centro de Informações da Aeronáutica e Destacamento de Operações e Informações/DOI do I Exército), que se mantiveram durante o período militar como centros de tortura e morte. Olhando para trás, é difícil compreender a falta de reação da sociedade, que a tudo se acomodou. Mas, como veremos adiante, a denúncia feita no presente ainda não é tranquila. 
A CNV denunciou os responsáveis pelas torturas e morte de Rubens Paiva, todos militares, mas não teve poder de indiciar todos os envolvidos. Um deles, já falecido na época da investigação, havia sido condecorado com a Medalha do Pacificador. ${ }^{8} \mathrm{O}$ filho lembra-se do pai como sendo um homem calmo, bom, engraçado, simpático e risonho, e nos traz as informações de seu desaparecimento em sua história de vida. Em que medida são as memórias do filho confiáveis?

Ao procurar gravar diversos conjuntos de três letras, que não apresentavam qualquer sentido, o psicólogo Hermann Ebbinghaus (1999), no final do século XIX, estabeleceu a curva do esquecimento, em que a memória apresenta um rápido declínio na primeira hora após o aprendizado, seguido de outro mais lento e gradual. Seu experimento mostrou que há uma perda natural e contínua da memória ao longo do tempo. Identificou ainda que a exposição repetitiva dos grupos de letras favorecia a memória e que, no processo, as últimas sequências gravadas provocavam esquecimento das anteriores. Seus estudos continuam atuais. Recentemente, o psicólogo Daniel Schacter (2001), a partir de um balanço dos estudos sobre a memória, sistematizou sete falhas principais: três relacionadas ao esquecimento (perda contínua da memória, falta de atenção e bloqueio), e quatro inerentes às formas de lembrar (má interpretação, sugestão, bias e persistência de memórias indesejáveis). Em suma, memórias são limitadas, estão relacionadas à atenção que damos aos eventos no momento em que os vivenciamos, e podem ser bloqueadas por emoções, como experiências traumáticas. Além disso, dependem das interpretações feitas no presente. Por que confiar nas memórias?

$\mathrm{O}$ autor de uma biografia traz na memória as vivências pessoais, que são partes de um contexto bem mais amplo e procura a unidade onde só há fragmentos. Estes são interpretados e reinterpretados à medida que passado e presente se encontram. Esta consciência do caráter incompleto e de mudança contínua das biografias - presente em análises como as de Beatriz Sarlo (2007), que se preocupou com a onda subjetivista e memorialista - aparece também no livro de 2015 de Marcelo Rubens Paiva. Logo após descrever a detenção de seu pai, quando tinha apenas 11 anos, ele tece comentários sobre como um fato que acontece hoje pode ser relido de outra forma amanhã e como pensamos hoje com a ajuda de uma parcela pequena do nosso passado (Paiva, 2015: 117).

Lembrar e esquecer são as duas faces do mesmo processo. Lembramos porque temos um aparelho seletivo para as memórias, ou seja, a capacidade

\footnotetext{
${ }^{8}$ Segundo relatório preliminar de pesquisa da CNV de 27 de fevereiro de 2014, consultado a 08.08.2019, em http://cnv.memoriasreveladas.gov.br/relatórios.html.
} 
de esquecer. Memórias não trazem o passado com a precisão de uma máquina fotográfica. O relato biográfico é inegavelmente incompleto, pessoal e subjetivo. Ele não substitui e nem tem as mesmas características de uma narrativa da história, que se preocupa com os vazios, inconsistências e veracidade da leitura. ${ }^{9}$ O relato de Marcelo Rubens Paiva não tem a intenção de propiciar a história da ditadura militar, aliás seu foco principal é a relação com sua mãe. Contudo, apesar do relato pessoal, o autor nos permite olhar para o passado que não está presente no registro oficial. Através de sua procura por informações relacionadas a seu pai, percebemos sua indignação em presenciar uma versão do passado que negava a tortura e a ocultação do cadáver, seu drama pessoal, assim como a passividade da população, que, segundo ele, aceitava a mentira por medo, preguiça ou falta de caráter.

Como sustentado pela família Paiva, o assassinato do deputado federal Rubens Paiva pelo Estado não foi um crime apenas contra eles, mas contra o país. Ao descrever a trajetória de sua família, Marcelo traz à tona as disputas, conflitos e violações que estão presentes na sociedade. Não há como não perceber a história do filho, por mais pessoal que seja, como a história de uma nação. A sua narrativa nos faz refletir sobre os valores e normas presentes na sociedade.

\section{Pós-memória ou a lembrança que se transmite pelos afetos}

No romance K.: relato de uma busca, de 2011, Bernardo Kucinski conta a história de um pai, "K.", à procura da filha, desaparecida nos anos 1970, durante a ditadura militar brasileira. O título $K$. remete ao nome do pai e pode ser compreendido como uma metáfora do mundo incompleto e enigmático responsável pelo desaparecimento da filha. Ana Rosa Kucinski, irmã do autor, e seu marido Wilson Silva desapareceram em 1974, assim como outros militantes presos, torturados e mortos pelos órgãos de segurança nacional. $\mathrm{O}$ romance não traz os personagens reais, mas o fictício $\mathrm{K}$. nos leva a uma imersão no universo de arbitrariedades e atrocidades da ditadura militar.

$K$. foi traduzido para diversas línguas e tem sido o objeto de diversas análises dentro do campo da crítica literária, que ressaltam o estilo da narrativa entre o real e o fictício. ${ }^{10} \mathrm{O}$ objetivo aqui é resgatar sua contribuição para os estudos da memória. No Brasil, a anistia negociada no momento de transição

\footnotetext{
9 Ver, por exemplo, a diferença entre história, como registro do passado através de métodos e compromisso com as fontes, e memória, como releitura constante do passado no presente, em autores como Maurice Halbwachs (1968) e Pierre Nora (1984).

${ }^{10}$ Ver, por exemplo, Russo (2017).
} 
do governo militar para o civil garantiu a não punição de criminosos, e foi responsável pelo apagamento de registros de torturas, mortes e ocultação de cadáveres. Arte e ficção têm cumprido um papel fundamental neste contexto, pois podem tornar visíveis violações, traumas e sofrimentos que não têm registro; em outras palavras, as escritas literárias têm ressuscitado os mortos e desaparecidos.

Theodor Adorno (1998) afirmou a impossibilidade da poesia após Auschwitz. No romance de Kucinski, K. admite não ser capaz de fazer literatura com o desaparecimento da filha, um impedimento moral. Alguns autores percebem a possibilidade da escrita do passado através de seus descendentes. As experiências recalcadas pela dor da primeira geração não são narradas, não são capazes de gerar poesia, mas elas são transmitidas para filhos e familiares próximos e estes são capazes de escrever sobre elas. Ao escrever sobre a pós-memória, Marianne Hirsch (2008) enfatizou que o conhecimento do passado aparece de maneira mais distanciada e reflexiva na segunda geração, superando as lembranças reprimidas pela dor e sofrimento. Dentre os diferentes tipos de memória, Ricoeur analisou também o par “evocação/recordação". Desta vez, trata-se de pensar não apenas os diferentes níveis de consciência presentes na memória, mas a chegada do passado sem ser convocado (Ricoeur, 2000). Há a lembrança que chega à consciência sem ter sido evocada. A memória é transmitida porque ela não se vincula apenas à razão; está presente em gestos, em sentimentos, no movimento, na dança e na música (Taylor, 2003).

Kucinski é jornalista e foi assessor da Presidência da República durante o governo do Partido dos Trabalhadores (2003-2006), contudo não é ele, o irmão engajado, quem faz a denúncia do regime. Diferentemente de Paiva, ele não trouxe seu testemunho como irmão, ou mesmo como filho, mas construiu uma narrativa fictícia. Diferentemente de Kundera, por exemplo, o autor não se confunde com seu personagem. K., pai da filha desaparecida, personagem do romance, não era um militante, não participava de qualquer movimento político e não era nem mesmo um crítico do regime. Mais do que isso, ele não fazia a mínima ideia do engajamento da filha com a oposição ao regime. Ao utilizar o recurso ficcional da narrativa, o autor afasta-se do propósito de dar seu testemunho ou mesmo de representar o real de forma "verdadeira". Este seria impossível, devido até mesmo aos limites de fontes e testemunhos, uma vez que sua irmã foi assassinada e não deixou depoimentos. Kucinski fez o resgate do passado a partir de uma rede fictícia de tramas, que é mais densa do que qualquer descrição de fatos que tivesse por base o real. A fantasia, contudo, apresenta-se em consonância com fatos políticos e sociais que se reconhecem como verdadeiros. O sofrimento cotidiano 
do pai está no centro do romance do filho. É através dele e junto com ele que o leitor vai sendo notificado dos espancamentos brutais, dos gritos, da violação do corpo da filha, da intensa crueldade e indignidade humana.

Marcelo Rubens Paiva e Bernardo Kucinski, em estilos diferentes, lidam com o mesmo tema: a dor daquele que luta pelo direito de enterrar seu ente querido. Os mortos precisam estar presentes para que o luto ocorra, mas o que fazer quando os corpos desaparecem? Como um pai ou um filho podem lidar com a perda contínua, ferida aberta que não se fecha? Em Kucinski, amor e responsabilidade aparecem no romance através dos vários questionamentos que o pai faz sobre seu relacionamento com a filha. Não deveria ter ele sido mais presente, mais atento? Como pode negligenciar o cuidado com aquela que lhe era tão preciosa? Porque não soubera do casamento da filha?

Para ocultar os assassinatos, as autoridades faziam desaparecer os corpos. Registros se mantiveram apenas entre os militares, que continuam até hoje com controle sobre os arquivos daquele período. Até aos dias atuais, familiares de muitos daqueles que desapareceram ainda não têm conhecimento sobre as circunstâncias integrais dos desaparecimentos, assassinatos e do local onde poderão ser encontrados eventuais restos mortais. Até hoje, não houve comprometimento com o acesso à verdade e à justiça por parte do Estado brasileiro, nem reconhecimento dos assassinatos, nem fornecimento de atestados de óbitos, nem julgamento dos autores dos crimes cometidos.

Os dois autores acima referidos trazem também entrelaçados testemunhos pessoais e situações coletivas. À medida que K. vai batendo à porta das autoridades, das diversas instituições sociais e religiosas, dos grupos profissionais e familiares, fica evidente no conto que a lembrança de $K$. não diz respeito apenas a ele, mas a todos nós, pois ela traz de volta a dignidade humana para todos que o seguem em sua jornada. A filha era professora de química e K. denuncia o distanciamento de seus colegas, cujo mal-estar aparece apenas pela impossibilidade de dar sequência à burocracia universitária e ocupar a vaga da desaparecida. A imprensa não denunciava, testemunhas calavam-se.

No romance, K. chegara ao Brasil jovem, fugindo da ameaça nazista. Como imigrante polonês e judeu, ele acaba por se deparar novamente com a violência destruidora de um Estado, com contornos semelhantes ao da catástrofe deixada para trás. Em algum momento desabafa, pois se vê diante de uma situação inusitadamente cruel, pois até os nazistas, que reduziam suas vítimas a cinzas, registravam os mortos. Denunciou a falta de sensibilidade de um rabino, que não permitiu a colocação da matzeivá sobre o túmulo, sabendo este que o corpo não estaria presente - o que era 
impossível -, mas que a lápide permitiria a lembrança de sua filha. K. traz assim à tona a dificuldade de autoridades religiosas responderem ao novo tipo de violência. Como aprender com o passado, se esse nunca se repete da mesma forma? Que tipo de aprendizado o passado oferece?

\section{Arquivos e herança cultural}

Qual é o papel dos arquivos na luta contra o esquecimento? Arquivos e bibliotecas se multiplicaram nas últimas décadas. Os arquivos fazem parte de um aparato social que consolida a memória coletiva. O historiador Pierre Nora enfatizou a importância de lugares da memória na constituição da nação francesa. Monumentos, patrimônio arquitetônico, paisagens, músicas, culinária, folclores, datas, personagens históricos, tradições e costumes foram analisados como formadores de regras de sociabilidade e sentimentos coletivos (Nora, 1984). Os arquivos se inscrevem nas memórias e hierarquias formadas. Embora estes sejam artefatos da consolidação de uma memória de longa duração, também neste campo podemos identificar disputas e conflitos.

Entre as décadas de 1960 e 1980, os países da América Latina passaram por ditaduras militares. Uma das marcas destes regimes foi a tortura e morte de milhares de pessoas que se opuseram aos governos autoritários que existiam. No Brasil, a ditadura se estendeu de 1964 até 1985. Mesmo antes da abertura democrática, diversos grupos e instituições foram criados com o intuito de denunciar os atos de exceção praticados pelos militares. O projeto "Brasil: Nunca Mais" contou com lideranças religiosas, como o cardeal Dom Paulo Evaristo Arns, o rabino Henry Sobel e o pastor Jaime Wright. Em 1985, a organização publicou um relatório com várias denúncias que revelava a extensão da repressão política. O Comitê Brasileiro de Anistia (fundado em 1978) exerceu um papel crucial ao denunciar os atos de violação dos direitos humanos e ao lutar pela anistia ampla, geral e irrestrita de todos aqueles atingidos pelo regime. A Lei de Anistia foi decretada em 1979 de forma controversa, pois não foi ampla nem irrestrita e anistiou não só os torturados, mas também os torturadores. O país passou pelo que denominaram de transição tutelada, pois os militares mantiveram instituições, autonomia e privilégios. Em 1985, ex-presos políticos e familiares de mortos e desaparecidos criaram o Grupo Tortura Nunca Mais com o intuito de denunciar e cobrar do Estado punição para os que haviam torturado e assassinado presos políticos.

Apesar dessas importantes iniciativas, os processos de denúncia não fizeram parte dos arquivos do Estado no período de abertura política, tal como aconteceu em outros países da América Latina. Somente em 1995 
o Estado brasileiro reconheceu a morte de dezenas de pessoas por participação política em oposição à ditadura militar e criou a Comissão Especial sobre Mortos e Desaparecidos Políticos (CEMDP), instituição ligada à Secretaria de Direitos Humanos. E, apenas em 2012, no governo da presidente Dilma Rousseff, ela própria torturada durante a ditadura, foi instalada a CNV com a competência de apurar as violações de direitos humanos ocorridas no passado. A comissão teve caráter provisório, sem competência para encaminhar punições. O primeiro relatório da Comissão, entregue à presidência da República dois anos depois, causou um grande impacto, pois confrontou os arquivos militares, denunciou nominalmente diversos torturadores e elucidou casos de violação, assassinato e desaparecimento de corpos. O documento trouxe a recomendação imperativa de que as Forças Armadas reconhecessem sua responsabilidade institucional nas graves violações de direitos humanos ocorridas ao longo dos anos de ditadura, uma vez que houve uma ação generalizada e sistemática de crimes contra a humanidade perpetrada pelo Estado. Em 2016, houve o impeachment da presidente Dilma Roussef e, a partir das eleições de 2018, com a eleição de Jair Bolsonaro, a volta de militares a diversas posições de poder.

Podemos dizer que a denúncia das violações aos direitos humanos ocorridos no passado não foi consolidada em arquivos, museus, memoriais e instituições de âmbito nacional. Poucas instituições foram criadas com este objetivo, como, por exemplo, o Memorial da Resistência de São Paulo. ${ }^{11}$ Em dezembro de 2018, o Memorial fez uma ampla convocação para um debate, cujo título era "Quem conta a história da ditadura?". A proposta de trabalhar com documentos e testemunhos e discutir a metodologia de construção do conhecimento histórico alcança especialistas, mas não parte substantiva da população. Mesmo no início do atual governo de Bolsonaro, observa-se a tentativa de manter viva a denúncia contra os atos criminosos da ditadura. Em abril de 2019, a CEMDP ${ }^{12}$ retificou quatro certidões de óbito, substituindo o termo "morte natural" por "morte não natural, violenta, causada pelo Estado brasileiro, no contexto de perseguição sistemática e generalizada à população identificada como opositora”. As certidões têm o intuito de promover a reparação imaterial e a justiça àqueles que sofreram violência.

\footnotetext{
${ }^{11}$ O Memorial é uma iniciativa do governo do Estado de São Paulo e dedica-se à preservação das memórias da resistência e da repressão políticas do Brasil através de ações como construção de um centro de referências, levantamento de lugares da memória, coleta regular de testemunhos, exposições e ações educativas e culturais. Desde 2009, é membro da Coalizão Internacional de Sítios de Consciência. Consultado a 03.06.2019, em http://memorialdaresistenciasp.org.br/memorial/ default.aspx?mn=4\&c=83\&s=0\#.

${ }_{12}$ Consultado a 30.01.2020, em http://pfdc.pgr.mpf.mp.br/informativos/edicoes-2019/maio/ familiares-de-desaparecidos-politicos-recebem-certidoes-de-obito-retificadas.
} 
Qual o papel dos arquivos na consolidação de uma determinada memória sobre o passado? Dentre os arquivos bem consolidados sobre violações de direitos humanos encontra-se aquele que pertence ao Yad Vashem, memorial oficial de Israel, que contém o Museu da História do Holocausto, vários outros memoriais, um instituto de pesquisa, um centro educacional, uma biblioteca e uma editora, entre outros órgãos. Em 1953, o parlamento de Israel aprovou a criação deste memorial para que ninguém se esquecesse da Shoah. A base de dados, que está acessível on-line, disponibiliza ao público mais de 3,3 milhões de nomes de vítimas; os arquivos têm mais de 74 milhões de páginas, 350 mil fotografias e mais de 46 mil testemunhos gravados em áudios e vídeos. O Museu da História do Holocausto faz parte de uma nova museologia que enfrenta a tarefa de sensibilizar seus visitantes, não só com textos e informações, mas também com ambientações que despertam os diversos sentidos, de forma a chamar a atenção para o sofrimento e a tragédia que são narradas.

Em 2005, a Assembleia Geral das Nações Unidas elegeu o 27 de janeiro - data da libertação do campo de concentração de Auschwitz - como Dia Internacional em Memória das Vítimas do Holocausto. Além dos arquivos, romances, depoimentos, pesquisas acadêmicas e filmes sobre a Shoah, o memorial disponibiliza informações sobre o passado. A partir da lembrança e da preservação dos suportes da memória, acreditou-se que o assassinato em massa de judeus - ou de qualquer povo, nação ou etnia - não se repetiria jamais.

Contudo, a afirmação de que há uma relação direta entre a preservação da memória de violações de direitos e a formação de uma cultura de não violência precisa ser cuidadosa. É necessário analisar a singularidade de cada caso apresentado. O processo de institucionalização das denúncias às violações foi maior em determinados países e esse processo certamente garante uma resistência maior à violência do Estado e aos apagamentos da memória. Mas esta não é uma equação única. O conflito entre israelenses e palestinos tem alcançado níveis de violência inimagináveis e proporcionado inúmeros casos de violação de direitos. O massacre de Sabra e Chatila (1982), por exemplo, quando uma milícia libanesa dizimou barbaramente uma população inteira de civis palestinos e libaneses, cercada e impedida de fuga pelo exército de Israel, nos mostra que a cultura do "nunca mais" é difícil de alcançar. É Todorov que uma vez mais nos lembra que o mal retorna sem se deixar reconhecer. Após Auschwitz, ele aponta novos exemplos de violência inútil, como o regime comunista de Pol Pot, no Camboja, ou o genocídio de Ruanda (Todorov, 2002: 216-217). Os diversos testemunhos deixados e a construção de arquivos e museus não garantiram um comportamento 
diferenciado em novos conflitos, que surgem como situações singulares acompanhadas de novas levas de violações.

Arquivos guardam, portanto, determinadas memórias e são resultado de processos seletivos, apresentam falhas, constituem-se por fragmentos e resistem aos diversos usos. O encontro com o passado, como vimos, não pode estar limitado à existência de fontes documentais. Além disso, o aprendizado que se pode ter com os arquivos depende dos contextos em que se inserem. A pesquisadora alemã Aleida Assman, em seus estudos sobre memória cultural, fez uma distinção interessante entre nações que se consolidam a partir de elementos comuns daquelas que rememoram feridas como forma de alcançar uma unidade. Identidades constituídas sobre eventos traumáticos podem trazer à tona tanto um maior respeito pelos vizinhos, como seu oposto, um potencial mais agressivo, pois sociedades também podem se tornar mais vingativas em função de frustrações passadas. A autora, ao longo do texto, procurou mostrar que não há uma relação direta nem entre arquivo e forma de lembrar, nem entre esta e ações coletivas (Assman, 2008). Destacou com isso a relativa autonomia que podem ter os arquivos em relação ao presente. Ainda assim, advertiu a autora, como a capacidade de armazenamento dos arquivos supera a capacidade de uso, eles representam uma "meta-memória", que garante diversidade e precisa ser mantida, pois sempre poderá ser alvo de destruição por proposições autoritárias que procuram impor uma versão única da história (ibidem).

\section{Notas finais: o dever da memória ou a memória como direito}

Primo Levi deixou um dos mais fortes testemunhos já escritos sobre a Shoah (Levi, 1990). Na abertura de seu livro Os afogados e sobreviventes, ele descreve a incredulidade do público diante das primeiras informações sobre os campos de concentração. Esta dificuldade de apreensão do que lá acontecera forçou a lembrança de muitos que por lá passaram, como também a criação de arquivos. Testemunhos e arquivos, portanto, têm sido importantes objetos de luta contra o esquecimento. Como vimos, apesar de toda a atenção dada à "memória" nas últimas décadas, continuamos a enfrentar intolerância, conflitos étnicos, ódio, fanatismo, bem como usos e abusos da história.

Procuramos ao longo do texto mostrar que memórias precisam ser compreendidas como parte de processos múltiplos e complexos. Elas continuarão a ser disputadas, reiteradas, apagadas, e continuarão a resistir às diversas formas de uso e manipulação. Suportes da memória são construídos e organizados em instituições sociais que têm a função de formalizar determinadas narrativas sobre o passado, impedindo que estas fiquem sem 
registro e sejam esquecidas. Como sabemos, construções sociais não são estáveis, e com seu rompimento, novas narrativas se formam.

A partir da ascensão do fascismo, autores vinculados à Escola de Frankfurt procuraram compreender a violência inerente às novas formas de poder e partiram para a crítica da razão Ocidental, forma de pensamento incapaz de compreender o movimento da vida, ou seja, a relação dialética entre os indivíduos e seu meio social e que se desdobrava em razão positivista e barbárie. Walter Benjamin, que talvez seja o autor que tenha denunciado os problemas inerentes à escrita da história de forma mais incisiva, denunciou que a cultura e seus produtos, que envolvem os artefatos da memória, são sempre colocados ao serviço daqueles que não cessam de vencer (Benjamin, 1987). Ainda assim, acreditou que o dever da memória continuaria a ser acionado por aqueles que tinham seus direitos cerceados, fosse através de reminiscências ou memórias involuntárias (ibidem).

São bem conhecidas as críticas estabelecidas por Friedrich Nietzsche e reiteradas por Michel Foucault aos diversos usos do passado, tanto no que diz respeito à associação entre história e verdade, como à manutenção e veneração de monumentos e tradições (Nietzsche, 1983; Foucault, 1977). Ao propor a genealogia do poder, Foucault destacou a importância dos arquivos, embora atento às descontinuidades, rupturas e descentramentos presentes nas representações consolidadas por grupos hegemônicos e dominantes.

É importante compreendermos que por "memória" estamos denominando diferentes formas de pensamentos e de encontro com o passado, formas estas que fazem parte de processos mais amplos dos quais não temos pleno controle. Memórias são construídas, inventadas e resistem às construções do passado. Além disso, as memórias fazem parte dos processos históricos e são utilizadas como defesa e como "arma", por vencedores e vencidos. Não podemos compreender os diversos tipos de memória sem que estes estejam contextualizados em relação ao lugar e tempo em que se inserem.

No Brasil, a insegurança não advém dos fluxos migratórios e da ameaça externa, mas do perigo interno, isto é, há no Brasil uma elite econômica que teme a perda de privilégios e de status provocada por políticas distributivas. Neste contexto, a memória é associada tanto à resistência a governos autoritários e apagamentos do passado como à violência extrema de políticas de purificação cultural e toda sorte de fundamentalismo à medida que produz certezas sobre identidade social, valores e sobrevivência. Apesar dos testemunhos, do fenômeno da pós-memória, dos arquivos e da tentativa de formação de uma cultura cívica contra os abusos da ditadura, essas iniciativas não garantiram o que denominamos "dever da memória". 
Se, por um lado, tenta-se eternizar o passado de povos e nações em monumentos e rituais, lembrando mais uma vez a advertência de autores tão diversos como Nietzsche, Benjamin e Foucault, por outro, são inúmeras as manifestações contrárias à fixação do passado. Esse é um movimento que faz parte do processo histórico e que precisamos associar às diversas possibilidades da memória. Se pensarmos a memória como fixa e consolidada, diremos que ela fracassou. Mas se concluirmos que a memória, em todas as suas expressões, pessoais e impessoais, não é em si mesma nem interessada nem sacralizadora, diremos que ela continua sendo parte essencial de nossas lutas. Mais do que isso, considerando a relação constante entre presente e passado, veremos que há necessidade de uma abordagem sempre crítica para que o compromisso com o passado, também compreendido como dever da memória, se cumpra em prol de uma postura ética e moral apta a lidar com responsabilidades e políticas de reparação.

Revisto por Ana Sofia Veloso

\section{Referências bibliográficas}

Adorno, Theodor (1998), "Crítica cultural e sociedade”, in Prismas. São Paulo: Ática, 7-26. Tradução de Augustin Wernet e Jorge Mattos Brito de Almeida.

Assman, Aleida (2008), "Canon and Archive”, in Astrid Erll; Ansgar Nünning (orgs.),

Cultural Memory Studies: An International and Interdisciplinary Handbook. Berlin:

Walter de Gruyter, 97-107.

Benjamin, Walter (1987), “Teses sobre o conceito da história”, in Walter Benjamin Obras escolbidas. São Paulo: Brasiliense, 222-232. Tradução de Sergio Paulo Rouanet. Bergson, Henri Louis (1985), Matière et mémoire: essai sur la relation du corps à l'esprit.

Paris: Presses universitaires de France [orig. 1896].

Betto, Frei (1982), Batismo de sangue: guerrilha e morte de Carlos Marighella. Rio de Janeiro: Rocco.

Ebbinghaus, Hermann (1999), Memory. A Contribution to Experimental Psychology. Bristol: Thoemmes Press. Tradução de Henry A Ruger e Clara E. Bussenius.

Foucault, Michel (1977), "Nietzsche, Genealogy, History", in Language, Counter-Memory, Practice. New York: Cornell University Press, 139-164. Tradução de Donald F. Bouchard e Sherry Simon.

Gabeira, Fernando (1979), O que é isso companheiro? Rio de Janeiro: Codecri. Halbwachs, Maurice (1925), Les cadres sociaux de la mémoire. Paris: Felix Alcan. Halbwachs, Maurice (1968), La mémoire collective. Paris: Presses universitaires de France. Hirsch, Marianne (2008), "The Generation of Postmemory”, Poetics Today, 29(1), 103-122. 
Kucinski, Bernardo (2011), K.: relato de uma busca. São Paulo: Expressão Popular.

Kundera, Milan (1987), O livro do riso e do esquecimento. Rio de Janeiro: Nova Fronteira. Tradução de Teresa Bulhões Carvalho da Fonseca [orig. 1978].

Lavabre, Marie-Claire (2000), “Usages et mésusages de la notion de mémoire”, Critique Internationale, 7(1), 48-56.

Levi, Primo (1990), Os afogados e sobreviventes. Rio de Janeiro: Paz e Terra. Tradução de Luiz Sérgio Henriques.

Nietzsche, Friedrich (1983), "On the Uses and Disadvantages of History for Life", in Untimely Meditations. Cambridge: Cambridge University Press, 57-124. Tradução de R. J. Hollingdale.

Nora, Pierre (1984), Les lieux de mémoire. Paris: Éditions Gallimard.

Paiva, Marcelo Rubens (1982), Feliz ano velho. São Paulo: Brasiliense.

Paiva, Marcelo Rubens (2015), Ainda estou aqui. São Paulo: Alfaguara.

Pollak, Michael (1989), "Memória, esquecimento, silêncio", Estudos Históricos, 2(3), 3-15.

Ricoeur, Paul (2000), La mémoire, l'bistoire, l'oubli. Paris: Seuil.

Russo, Vicenzo (2017), "Pater, pátria e memória como patrimônio: sobre K.: relato de uma busca, de Bernardo Kucinski”, Estudos de Literatura Brasileira Contemporânea, 50, 35-46.

Sarlo, Beatriz (2007), Tempo passado: cultura do passado e guinada subjetiva. São Paulo/ Belo Horizonte: Companhia das Letras/UFMG.

Schacter, Daniel L. (2001), The Seven Sins of Memory: How the Mind Forgets and Remembers. New York: Houghton Mifflin Company.

Schacter, Daniel L.; Tulving, Endel (1994), Memory Systems. Cambridge: MIT Press.

Seligmann-Silva, Márcio (org.) (2003), História, Memória e literatura: o testemunho na era das catástrofes. Campinas: Editora Unicamp.

Sirkis, Alfredo (1980), Os carbonários: memórias da guerrilha perdida. Rio de Janeiro: Global.

Tapajós, Renato (1975), Em câmara lenta. São Paulo: Alfa Ômega

Taylor, Diana (2003), The Archive and the Repertoire: Performing Cultural Memory in the Americas. Durham, NC: Duke University Press.

Todorov, Tzvetan (1995), Les abus de la mémoire. Paris: Arléa.

Todorov, Tzvetan (2002), Memória do mal, tentação do bem: indagações sobre o século XX. São Paulo: Arx. Tradução de Joana Angélica D’Avila.

Tulving, Endel (1972), "Episodic and Semantic Memory", in Endel Tulving; Wayne Donaldson (orgs.), Organization of Memory. New York: Academic Press, 381-403. 
Artigo recebido a 01.07.2019

Aprovado para publicação a 16.10.2019

\section{Myrian Sepúlveda dos Santos}

Instituto de Ciências Sociais, Universidade do Estado do Rio de Janeiro

Rua São Francisco Xavier, 524, UERJ, Maracanã, Rio de Janeiro, CEP: 20550-013 Brasil

Contacto: myrian@uerj.br

ORCID: http://orcid.org/0000-0002-3215-4042

\section{The Return of the Nightmare: A Study on the Struggle of Memory versus Forgetting}

The article offers an analysis of different types of memory, in the face of issues related to memory politics, the falsification of history, and the notion of collective amnesia in the current context of economic crisis, worker fragmentation and predominance of social networks in communicative processes. It seeks to demonstrate that there are a number of ways in which a society can fight against forgetting, such as through testimonial literature, post-memory cases, and archives. In any of these cases, a critical approach is needed so that commitment to the past, also understood as a duty of memory, is fulfilled in favor of an ethical stance able to deal with reparation policies and responsibilities. Keywords: archives; collective memory; cultural heritage; testimonial literature.

\section{Le retour du cauchemar: une étude sur la lutte pour la mémoire contre l'oubli}

Cet article propose une analyse des différents types de mémoire face aux questions liées aux politiques de mémoire, à la falsification de l'histoire et à l'amnésie collective dans le contexte actuel de crise économique, de fragmentation des travailleurs et de prédominance des réseaux sociaux dans les processus de communication. Nous nous attachons à démontrer qu'il existe plusieurs façons d'une société lutter contre l'oubli: à travers la littérature de témoignage, de cas de post-mémoire et d'archives. Dans tous les cas, il s'avère nécessaire d'adopter une approche critique afin que l'engagement avec le passé, également considéré en tant que devoir de la mémoire, soit respecté en faveur d'une posture éthique capable de faire face aux responsabilités et aux politiques de réparation.

Mots-clés: archives; littérature de témoignage; mémoire collective; patrimoine culturel. 
